\title{
Die Finanzkrise und die Handlungsfähigkeit des Nationalstaats
}

\author{
Einleitung zu den folgenden Beiträgen
}

\author{
Renate Mayntz • Wolfgang Streeck
}

Es besteht weitgehend Übereinstimmung darüber, dass die Finanzkrise, die sich zu einer globalen Wirtschaftskrise auszuweiten droht, durch das Zusammenspiel einer Reihe ökonomischer Prozesse mit den strukturellen und institutionellen Merkmalen des internationalisierten Finanzsystems entstand. Mit den Ursachen dieser Krise befasst sich inzwischen eine umfangreiche Literatur. In den folgenden Beiträgen wird eine andere Frage aufgegriffen, nämlich die nach den absehbaren Auswirkungen der Finanzkrise und der von ihr ausgelösten politischen Reaktionen auf die Handlungsfähigkeit des Nationalstaats.

Streng genommen kann ,,der Nationalstaat“ natürlich nicht handeln; wenn die Handlungsfähigkeit des Nationalstaats zur Diskussion steht, geht es deshalb eigentlich nicht um ,den Staat“, das Gesamt aller politischen und öffentlichen Institutionen, sondern um die in einem Land zum Treffen verbindlicher Entscheidungen befugten politischen Institutionen oder Akteure. Deren Handlungsfähigkeit wurde genau in dem Maße zum Problem, in dem man vom Leitbild des Interventions- oder Steuerungsstaats ausging. Wegen der zunehmenden Internationalisierung, der wachsenden Bedeutung des „Regierens jenseits des Nationalstaats“" und nicht zuletzt infolge der durch die ökonomische Globalisierung bedingten Verschiebung im Verhältnis zwischen Politik und Ökonomie galt die Handlungsfähigkeit dieses Staats seit längerem insbesondere der Wirtschaft gegenüber als eingeschränkt. Das war keine von den großen westlichen Nationalstaaten erlittene, sondern eine insbesondere von den Ländern mit starken Finanzstandorten aktiv vorangetriebene Entwicklung, hoffte man doch, durch Liberalisierung das Wirtschaftswachstum und durch Deregulierung die eigene Finanzbranche im internationalen Wettbewerb zu stärken. Als die sich schon länger anbahnende jüngste Bankenkrise offenbar wurde und mit dem Zusammenbruch der Wall Street-Bank Lehmann Brothers eine globale Bedrohung des Finanzssystems entstand, reagierte die Politik nolens volens nach dem Imperativ des Prinzips ,too big to fail“ und schnürte finanzielle Rettungspakete zuvor unvorstellbaren Ausmaßes. Das staatliche Krisenmanagement, das bis jetzt einen als unmittelbare Bedrohung wahrgenommenen Totalzusammenbruch des gesamten Finanzsystems verhindert und die Auswirkungen der Krise auf die Realwirtschaft wenigstens eingedämmt hat, scheint die zuvor konstatierte Erosion staatlicher Handlungsfähigkeit beendet und eine Rückkehr des Staates eingeläutet zu haben. 
In den beiden folgenden Beiträgen, die auf ein gemeinsames Diskussionspapier für eine Forums-Veranstaltung der Sozialwissenschaftlichen Klasse der Berlin-Brandenburgischen Akademie der Wissenschaften am 12. November 2009 zurückgehen, wird gefragt, was es mit dieser Rückkehr, dem möglichen Wiedererstarken des Nationalstaats auf sich hat: Was sind die heute schon erkennbaren, mittel- und langfristigen Auswirkungen der Krise auf den Status und die künftige Handlungsfähigkeit des modernen Nationalstaats? Staatliche Handlungsfähigkeit kann binnenstaatlich ebenso wie im Kontext internationaler Beziehungen zum Problem werden; sie kann durch Ressourcenmangel (fiskalisch) eingeschränkt werden oder durch die Unfähigkeit zur regulierenden Intervention. Der Beitrag von Wolfgang Streeck befasst sich mit den Folgen der Finanzkrise - genauer: den Folgen der Versuche ihrer Bewältigung - für die fiskalische Handlungsfähigkeit des Staates nach innen. Aber nicht jede Politik setzt Geld voraus; staatliche Handlungsfähigkeit erweist sich auch durch die Fähigkeit zur gesetzlichen Normierung - die Kosten für regulative Politik fallen vor allem bei ihren Adressaten an. Im Beitrag von Renate Mayntz geht es deshalb um die Rolle, die nationale politische Akteure bei der Reform der Finanzmarktregulierung spielen. Erst wenn beides bedacht wird, die von der Verfügbarkeit finanzieller Ressourcen abhängende Handlungsfähigkeit des Staats nach innen und seine Fähigkeit, allein oder gemeinsam mit anderen Staaten das zunehmend globalisierte Finanzsystem zu regulieren, kann man etwas darüber sagen, wie sich nach heutiger Kenntnis die Finanzkrise auf die Handlungsfähigkeit des (modernen westlichen) Nationalstaats auswirken wird. Dabei zeigen beide Aufsätze, dass „,die Krise“ keine Trendwende zurück zum Primat der Politik ist, sondern dass die staatlichen Reaktionen auf diese Krise ins Muster bereits länger laufender Prozesse passen; das gilt sowohl für den langfristigen Trend zur Staatsverschuldung wie für die veränderte Rolle des Staates im Rahmen einer zunehmend internationalisierten Wirtschaft. Die Finanzkrise manifestiert und verstärkt zugleich Entwicklungen, die über sie hinausreichen. 